\title{
Interchangeability between paracetamol tablets marketed in Palestine. Is there a quality reason for a higher price?
}

A. Zaid, ${ }^{1}$ T. Rinno, ${ }^{2}$ N. Jaradat, ${ }^{1}$ S. Jodeh ${ }^{2}$ and S. Khammash ${ }^{7}$

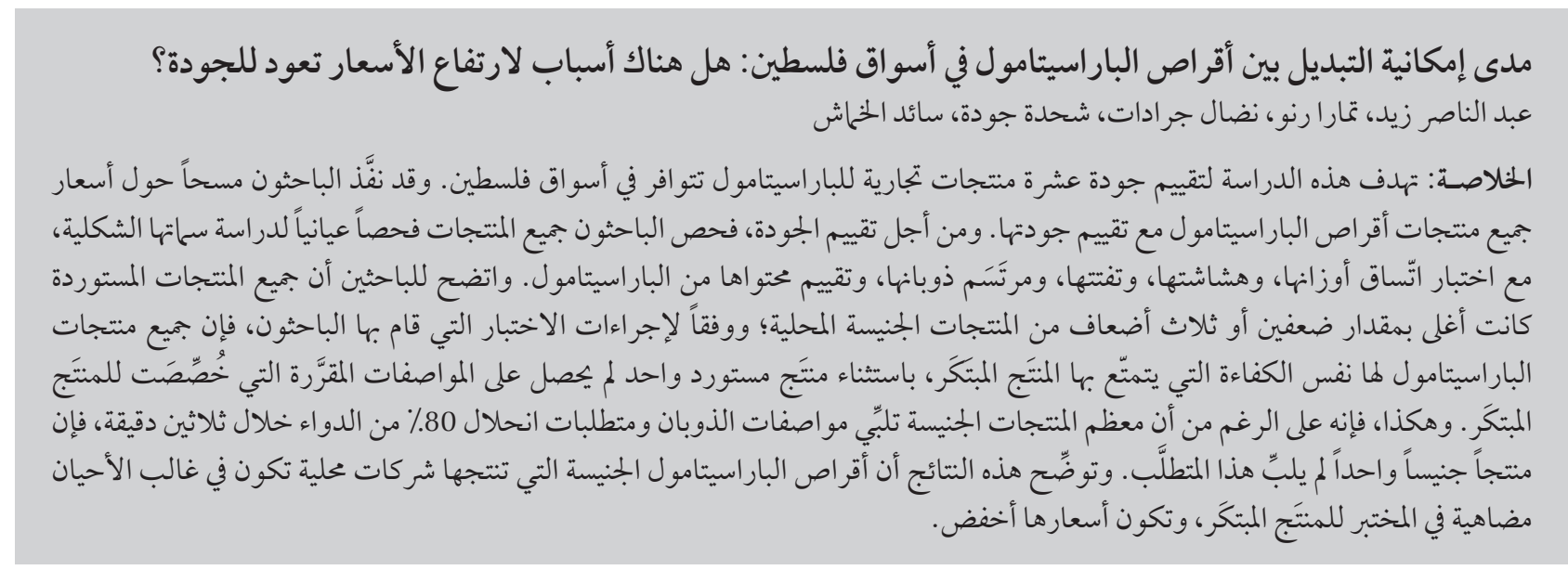

ABSTRACT The objective of this study was to evaluate the quality of 10 commercial paracetamol products available on the Palestinian market. We carried out a survey on the price of all paracetamol tablet products and assessed their quality. To assess quality, all products were examined visually for their organoleptic properties, tested for weight uniformity, friability, disintegration, and dissolution profile, and assayed for paracetamol content. All imported products were 2 to 3 times more expensive than the locally produced generic products. Based on our testing procedure, all paracetamol products were equivalent to the innovator product except for 1 imported product which fell below the approved specifications developed for the innovator product. Although the majority of generic products met the dissolution specification requirement that $80 \%$ of the drug must dissolve in 30 minutes, 1 generic product failed. These results demonstrate that generic paracetamol tablets produced by local manufacturers are often comparable in vitro to the innovator product and have lower costs.

Interchangeabilité des comprimés de paracétamol commercialisés en Palestine. Une raison qualitative peut-elle expliquer les différences de prix?

RÉSUMÉ L'objectif de la présente étude était d'évaluer la qualité de dix produits de paracétamol commercialisés sur le marché palestinien. Nous avons mené une enquête sur le prix des comprimés de paracétamol et avons évalué leur qualité. Pour évaluer leur qualité, tous les produits ont été examinés visuellement pour leurs propriétés organoleptiques, analysés pour l'uniformité en matière de poids, de friabilité, de désintégration et de dissolution. Le dosage en paracétamol a également été mesuré. Tous les produits importés étaient deux à trois fois plus chers que les génériques produits localement. Selon notre procédure d'évaluation, tous les produits de paracétamol étaient équivalents au produit innovateur, à l'exception d'un produit importé dont les propriétés n'étaient pas conformes aux spécifications prévus dans les approuvées pour le produit innovateur. Tous les produits génériques sauf un étaient conformes à l'exigence de dissolution spécificateurs selon laquelle 80 \% du comprimé doit être dissous en 30 minutes. Ces résultats révèlent que les comprimés de paracétamol génériques produits par des fabricants locaux sont souvent comparables in vitro au produit innovateur et moins chers. 


\section{Introduction}

Paracetamol (acetaminophen) is one of the most popular and most widely used analgesic and antipyretic drugs [1]. It is well absorbed from the proximal small intestine and is not subject to significant first-pass metabolism in the liver. Its oral bioavailability is estimated at 63\%-89\% in adults [2]. Paracetamol is also very cheap and readily available as an overthe-counter preparation. Therefore, it ranks as one of the most commonly used analgesic medications in Palestine. In fact, 10 paracetamol tablet products are available on the Palestinian pharmaceutical market, and this will probably increase in the future as manufacturers watch prescriptions for paracetamol increase. Nine of these products are generic and 1 is the innovator product.

The marketing of generic drug products registered by national drug agencies in developing countries has its attendant problem of ascertaining quality to determine their interchangeability [3]. In fact, all generic products for an active pharmaceutical ingredient should show comparable clinical responses, especially when compared with the original brand $[4,5]$. Accordingly, drugs having more than 2 generic products should be analysed for biopharmaceutical and chemical equivalence to ascertain their interchangeability. This analysis ensures that any of the generic products can be used interchangeably, especially when some of these products are locally manufactured.

It has been observed that most locally manufactured generic products are less expensive than imported products. Accordingly, this may raise the suspicion of non-equivalent performance. According to the guidelines of regulatory agencies such as the Food and Drug Administration, the prediction of the in vivo bioavailability of drugs from an oral solid dosage form depends on its in vitro dissolution profile [6]. Dissolution testing of drug products plays an important role as a quality control tool to monitor batch-to-batch consistency of drug release from a dosage form and as an in vitro surrogate for in vivo performance [7].

To assess out hypothesis, we surveyed the prices of the all paracetamol tablet products in the Palestinian market (generic and branded). We then checked several quality control parameters such as organoleptic characteristics, uniformity of weight and content, friability, hardness, disintegration and in vitro dissolution of all paracetamol tablet products to ascertain if the 10 products available on the Palestinian pharmaceutical market were interchangeable.

\section{Methods}

The study was carried out in March 2011 at the Centre for Drug Quality Control, An-Najah National University, Nablus, Palestine.

\section{Chemicals}

Before starting the study, the Palestinian Medicines Index (PMI) [8] and the Israeli Medical Index (MEDIC, 2010 edition) [9] were consulted to determine the brands which are currently available on the market. Paracetamol products having a label strength of $500 \mathrm{mg}$ were purchased from a retail pharmacy in Nablus city in Palestine. All tests were performed within product expiry dates.

Paracetamol powder was supplied by Jerusalem Pharmaceutical Company (Ramallah, Palestine). Monobasic potassium phosphate and potassium chloride were purchased from Merck, Germany. Methanol was of analytical grade and was purchased from Labscan, Ireland. High-performance liquid chromatography (HPLC)-grade water was used throughout the work (Labscan, Ireland). Simulated gastric fluid was prepared using $50 \mathrm{~mL} 0.2 \mathrm{M} \mathrm{KCl}$ and $13 \mathrm{~mL} 0.2 \mathrm{M} \mathrm{HCl}$. This was put in a $200 \mathrm{~mL}$ volumetric flask and diluted to volume using distilled water.

\section{Instruments}

The HPLC system (Isocratic manual injection, Pump LC-10ATvp, Photodiode Array Detector SPD- M10Avp; Schimadzo, Tokyo) was used for the analysis and quantification of paracetamol in the sample. Separation was accomplished with a $250 \mathrm{~mm} \times$ $4.0 \mathrm{~mm}, 5$ um (LiChro CART 250-4, Lichrospher 100, Merck KGaA, Darmstadt, Germany) column. Table 1 summarizes the analytical parameters used in this study. An electronic balance was used for weighing (A\&D Company Limited, Tokyo, Japan). Friability was evaluated using PTF-10E friability tester (Pharma Test, Hainburg, Germany). A model PTZ-2E disintegrator was used for disintegration testing and a dissolution apparatus PTW S3 (both Pharma Test) was used for drug release testing.

\section{Evaluation of organoleptic properties of paracetamol tablets}

The shape, colour and presence of black spots or breached edges of all tablet products were examined visually.

\section{Evaluation of physicochemical properties of paracetamol tablets}

To assess weight uniformity, tablets of each brand were weighed individually. The percentage deviation of the individual tablets from the mean was determined according to compendial requirements of the United States Pharmacopeia (USP) [8].

Tablet strength was evaluated by the friability test [10]. This test is important to evaluate the resistance of uncoated tablet upon exposure to mechanical shock or attrition. For friability, twenty tablets of each paracetamol product were weighed and subjected to abrasion. The apparatus was set at 24-26 revolutions/min and percentage powder loss was determined [10].

The disintegration time of paracetamol tablets was determined according 
to the procedure reported in the USP [10]. In summary, 1 tablet is placed in each of the 6 tubes of the basket and the disintegration apparatus was operated using water maintained at $37^{\circ} \mathrm{C}$. At the end of the time limit specified in the USP (15 minutes for uncoated tablets and 30 minutes for coated tablets); all of the tablets should disintegrate completely [10].

The amount of paracetamol in each tablet was determined according to the USP assay method using HPLC [10]. Twenty (20) tablets were accurately weighed and finely powdered, then an accurately weighed portion of the powder, equivalent to about $100 \mathrm{mg}$ of acetaminophen, was transferred to a $200 \mathrm{~mL}$ volumetric flask, about $100 \mathrm{~mL}$ of mobile phase was added, the mixture was shaken for $10 \mathrm{~min}$, then sonicated for about 5 min, diluted with mobile phase to volume, and mixed. A portion of this solution is passed through a filter having a $0.5 \mu \mathrm{m}$ or finer porosity, discarding the first $10 \mathrm{~mL}$ of the filtrate. The clear filtrate was injected into the HPLC system. Equal volumes (about $10 \mu \mathrm{L})$ of the paracetamol reference standard (paracetamol RS USP) and the assay preparation were injected separately. The major peaks were measured and the quantity of paracetamol calculated (Table 1).

\section{Dissolution test}

In vitro dissolution studies were carried out using a dissolution apparatus USP type II (PTWS3, Pharma Test, Hainburg, Germany) at a paddle speed of $50 \mathrm{rpm}$. Six tablets from each paracetamol product were used for the dissolution study. The dissolution medium was $900 \mathrm{~mL}$ phosphate buffer at $\mathrm{pH} 5.8$, maintained at $37 \pm 0.5^{\circ} \mathrm{C}$. In all dissolution experiments, $5 \mathrm{~mL}$ of the dissolution sample was withdrawn and replaced with an equal volume of fresh phosphate buffer ( $\mathrm{pH}$ 5.8) at regular intervals. The amount of paracetamol in the samples was determined using the above HPLC method [10]. The

\begin{tabular}{|c|c|}
\hline Parameter & Specification \\
\hline Column & $250 \mathrm{~mm} \times 4.0 \mathrm{~mm}, 5 \mu \mathrm{m}$ (Lichro CART 250-4, Lichrospher 100) \\
\hline Flow rate & $1.0 \mathrm{~mL} / \mathrm{minute}$ \\
\hline Injection volume & $20 \mu \mathrm{L}$ \\
\hline Wavelength & $243 \mathrm{~nm}$ \\
\hline Mobile phase & Water:methanol (3:1) \\
\hline
\end{tabular}

dissolution profiles of the different paracetamol product tablets were generated from the graph using Microsoft Office Excel.

\section{Results}

A total of 10 different commercial products of paracetamol tablets (500 $\mathrm{mg} /$ tablet) are available on the Palestinian pharmaceutical market. These were classified into imported and locally produced products and they were analysed for price. The results show a sizable difference in the price between the 2 groups, with the imported products being 2-3 times more expensive than the local products (Table 2).

The visual inspection of local and imported products showed no sign of defects in all tested tablets.

Weight uniformity of tablets was attained by all tested products with
$106.7 \%-110.1 \%$ of the label indication. Data are shown in Table 3. The friability results were within the pharmacopeial limits (a maximum loss of powder not more than $1 \% \mathrm{w} / \mathrm{w}$ with a range of $0.08 \%-0.40 \% \mathrm{w} / \mathrm{w}$. The assay of the local products was in conformity with the USP requirement, in the range $95.6 \%-102.5 \%$ with an average of $99.3 \%$ (Table 3 ). The assay of the imported products was in the range $90.8 \%-101.2 \%$ with an average of $96.6 \%$. The disintegration time for all paracetamol tablets was within the pharmacopoeial limits, ranging from $2.5 \mathrm{~min}$ to $9.0 \mathrm{~min}$, with an average of $3.5 \mathrm{~min}$ (local) and 4.2 minutes (imported). The highest disintegration time ( 9 min) was observed for product $\mathrm{F}$, which is an imported product. Tablet dissolution in 30 minutes ranged from $86.8 \%$ to $99.3 \%$, with only 1 product (F) failing the test. The dissolution data are presented in Table 4.

\begin{tabular}{lcc}
\hline \multicolumn{3}{l}{ Table 2 Price (per 20 tablets) of paracetamol products available on the Palestinian } \\
market, 2011 & Parcetamol product & Price (US\$) \\
\hline Source & A & 1.47 \\
Local & B & 1.47 \\
& C & 2.00 \\
& I & 1.47 \\
E & 1.47 \\
& J & 1.47 \\
Imported & F & 3.00 \\
& G & $-{ }^{\mathrm{a}}$ \\
& H & 3.20 \\
& E & 4.11 \\
\end{tabular}

${ }^{a}$ Received as gift from the United Nations Relief \& Works Agency. 


\begin{tabular}{|c|c|c|c|c|c|c|c|c|c|c|}
\hline \multirow[t]{2}{*}{ Parameter } & \multicolumn{10}{|c|}{ Product } \\
\hline & A & B & C & D & $\mathbf{E}$ & $\mathbf{F}$ & G & $\mathrm{H}$ & I & J \\
\hline Average weight (mg) & 552 & 543 & 634 & 598 & 607 & 545 & 627 & 541 & 554 & 550 \\
\hline Friability (\% loss of weight) & 0.20 & 0.30 & 0.19 & 0.08 & 0.10 & 0.40 & 0.34 & 0.12 & 0.15 & 0.20 \\
\hline Assay (\%) & 98.7 & 102.5 & 101.0 & 101.2 & 99.6 & 90.8 & 92.6 & 98.9 & 99.1 & 95.6 \\
\hline
\end{tabular}

\section{Discussion}

According to local community pharmacists and physicians (personal communication), patients usually prefer imported medications believing that these are better manufactured and have superior activity and safety compared with the locally manufactured products. These patients pay a higher price for imported products despite the poor economic circumstances of many of them. Pharmacists and physicians also have this belief and sometimes encourage patients to buy the imported products (personal communication). The objective of this study was to survey paracetamol tablet products present on the Palestinian market according to their price and to evaluate their quality according to pharmacopeial and non-pharmacopeial standards in order to identify the products that are interchangeable. The Palestinian Ministry of Health and the Department of Drug Control and Registration are the regulatory authorities that grant marketing authorization for branded and generic drug products. According to the current regulation [11], a product has to satisfy the compendial requirements for safety, purity and quality according to either the USP or the British Pharmacopeia. Additionally, a bioequivalence study is required to show that the generic is bioequivalent to the brand name drug according to the USA Food and Drug Administration and the European Medicines Agency [12,13]. The Palestinian regulatory authorities recognize and accept properly conducted studies performed in vitro to support in vivo data.

All paracetamol tablet products were assessed for general organoleptic properties and any sign of imperfections. In fact, these characteristics are essential for consumer preference and batchto-batch uniformity. The visual inspections showed that no differences were observed between the tested products.

The weight uniformity determination for the 10 commercial paracetamol products gave values that comply with

\begin{tabular}{|c|c|c|c|c|c|}
\hline \multirow{2}{*}{$\begin{array}{l}\text { Paracetamol } \\
\text { product }\end{array}$} & \multicolumn{5}{|c|}{$\%$ released at } \\
\hline & $5 \mathrm{~min}$ & $10 \mathrm{~min}$ & $15 \mathrm{~min}$ & $20 \mathrm{~min}$ & $30 \mathrm{~min}$ \\
\hline A & 50 & 69 & 86 & 92 & 97.9 \\
\hline B & 44 & 59 & 85 & 88 & 95.7 \\
\hline $\mathrm{C}$ & 39 & 49 & 86 & 92 & 96.6 \\
\hline I & 46 & 57 & 87 & 91 & 98.2 \\
\hline J & 48 & 61 & 86 & 89 & 93.3 \\
\hline $\mathrm{D}$ & 53 & 67 & 88 & 93 & 99.5 \\
\hline $\mathrm{E}$ & 56 & 83 & 87 & 91 & 96.8 \\
\hline $\mathrm{F}$ & 31 & 42 & 70 & 77 & 86.8 \\
\hline G & 41 & 52 & 85 & 87 & 90.9 \\
\hline $\mathrm{H}$ & 43 & 58 & 87 & 90 & 98.9 \\
\hline
\end{tabular}

the USP specification for uncoated tablets with a deviation less than 5\% from the mean value. A variation beyond the pharmacopoeial limits $( \pm 15 \%$ for 10 tablets) [11] indicates unacceptable pharmaceutical products.

Another important pharmacopoeial parameter to ascertain the quality of a dosage form is the drug content. Here, a clear difference was observed between local and imported products. In fact, all local produced paracetamol tablets were in conformity with the USP for paracetamol content. Surprisingly, 2 imported products showed low content of paracetamol on the lower accepted edge 90.8 and $92.6 \%$ for products $F$ \& G respectively.

In regard to tablet strength, all the tested products passed the friability test demonstrating that these products do not lose paracetamol during the transportation or handling process. But high tablet strength should not compromise disintegration in the stomach: tablets should disintegrate within the time limit prescribed by the USP, essential for achieving immediate drug absorption. The dissolution of the drug from oral solid dosage forms is necessary for drug bioavailability, especially for sparingly water soluble drugs such as paracetamol. For this reason, dissolution studies can give an idea of the amount of drug available for absorption after oral administration [14-16]. Drugs with poor dissolution profiles will not be sufficiently available in the body system to produce the desired therapeutic response $[17,18]$. The dissolution profile of all but 1 of the brands we tested in simulated gastric fluid was comparable. More precisely, 
the release of paracetamol in simulated gastric fluid from all local and imported brands was greater than $85 \%$ after 15 minutes, except for product $F$, which is an imported generic product. Kalantzi et al. suggested that paracetamol tablets may be biowaved from bioequivalence studies if the release of paracetamol from the tablets is greater than $85 \%$ in 15 minutes [19]. Accordingly, not all the tested products may need bioequivalence studies to ensure their interchangeability with the innovator product. But the imported product (F) is poorly manufactured and would require a change in its formulation to improve its dissolution behaviour; it should be subject to a bioequivalency study to determine whether it is interchangeable with the other paracetamol tablet products or not.

\section{Conclusion}

Our results demonstrate that paracetamol tablets produced locally are often comparable to the original brand (brand D, Panadol) in terms of quality, and thus they can be used interchangeably. Therefore there is no need to select a more expensive product to achieve a better therapeutic effect since these products may not meet the expected quality. However, bioequivalence studies would provide further evidence to ascertain the in vitro quality of these products, especially for the imported paracetamol tablet product (F) which showed lower quality than all the other tested products.

\section{Acknowledgements}

Funding: The authors did not receive any funding from any party.

Competing interests: None declared.

\section{References}

1. Bertolini A et al. Paracetamol: new vistas of an old drug. CNS Drug Reviews, 2006, 12(3-4):250-275.

2. Portolés A et al. A new high-absorption-rate Paracetamol 500mg formulation: a comparative bioavailability study in healthy volunteers. Current Therapeutic Research, 2003, 64(7):401-411.

3. Marketing authorization of pharmaceutical products with special reference to multisource (generic) products: a manual for drug regulatory authorities. Geneva, World Health Organization, 1998 (WHO/DMP/RGS/98.5) (http://apps.who.int/prequal/ info_general/documents/WHO_DMP_RGS_98_5_R.pdf, accessed 12 March 2013).

4. Zaid AN et al. Interchangeability of two $500 \mathrm{mg}$ amoxicillin capsules with one $1000 \mathrm{mg}$ amoxicillin tablet after a single oral administration. Indian Journal of Pharmaceutical Sciences, 2010, 72:414-420.

5. Tschabitscher D et al. Generika: qualitat, wirksamkeit, sicherheit und austauschbarkeit [Generic drugs: quality, efficacy, safety and interchangeability]. Wiener Klinische Wochenschrift, 2008, 120:63-69.

6. Babalola CP. Bioavailability and bioequivalence (BA/BE) assessment. In Olaniyi AA et al, eds. Towards better quality assurance of drugs in the 3rd millennium. Biopharmaceutical methods in drug quality assurance, 1st ed. Ibadan, Nigeria, Omoadade Printing Press, 2004.

7. Dressman JB et al. Dissolution testing as a prognostic tool for oral drug absorption: immediate release dosage forms. Pharmaceutical Research, 1998, 15:11-22.

8. Palestinian Medical Index (PMI). Ramallah, Union of Palestinian Pharmaceutical Manufacturers, 2010.

9. Monograph for Paracetamol. Herzliya, Medic Publications Ltd, http://www.medic.co.il/index.asp, accessed 24 March 2013).

10. United States Pharmacopeia and National Formulary USP 24-NF 19. Rockville, Maryland, United States Pharmacopeial Convention, Inc., 2000:1882-1883.
11. Registration requirements for new drug products. Data on file. Nablus, Drug Control and Registration Department, Palestinian Ministry of Health.

12. Guidance for industry. Waiver of in vivo bioavailability and bioequivalence studies for immediate-release solid oral dosage forms based on a biopharmaceutics classification system. Silver Spring, Maryland, Department of Health and Human Services Food and Drug Administration Center for Drug Evaluation and Research, 2000.

13. Note for guidance on the investigation of bioavailability and bioequivalence. London, European Agency for the Evaluation of Medical Products, 2000 (CPMP/EWP/QWP/1401/98).

14. Lindenberg $M$, Kopp S, Dressman JB. Classification of orally administered drugs on the World Health Organization Model list of Essential Medicines according to the biopharmaceutics classification system. European Journal of Pharmaceutics and Biopharmaceutics, 2004, 58:265-278.

15. Dressman J, Butler J, Hempenstall J, Reppas C. The BCS: where do we go from here? Pharmaceutical Technology, 2001, 25:68-76.

16. Shokhin I et al. Assessment of the possibility of using comparative in vitro dissolution kinetics (biowaiver) instead of in vivo bioequivalence evaluation for establishing the interchangeability of generic drugs. Pharmaceutical Chemistry Journal, 2011, 45(2):107-109.

17. Voegele D. Drug release in vitro-an aid in clinical trials? Methods and Findings in Experimental and Clinical Pharmacology, 1999, 21(1):55-62.

18. Moore JW, Flanner HH. Mathematical comparison of dissolution profiles. Oharmaceutical Technology, 1996, 20:64-74.

19. Kalantzi $L$ et al. Biowaiver monographs for immediate release solid oral dosage forms: acetaminophen (paracetamol). Journal of Pharmaceutical Sciences, 2006, 95(1):4-14. 